\title{
Numerical research on stiff adhesive point-fixings between glass and metal under uniaxial load
}

\author{
Jonas Dispersyn $\mathbb{D} \cdot$ Jan Belis
}

Received: 17 December 2015 / Accepted: 29 February 2016 / Published online: 15 March 2016

(C) Springer International Publishing Switzerland 2016

\begin{abstract}
Adhesive point-fixings are being used more frequently because of their numerous advantages compared to traditional bolted connections, such as a better load introduction, the absence of drilled holes in the glass, and increased thermal performances. With this research the mechanical behaviour of adhesive pointfixings between glass and metal under uniaxial load is investigated numerically. By supporting the model pivotally along a circumference equal to six times the diameter of the fitting, the entire connection is investigated. Up to now, only the adhesive layer has been studied, without bringing the influence of the stiffness of the glass panel into account. With a finite element method (FEM) a numerical model is validated by experimental results. A complete validated model is gained by performing the experiments for five different geometries with a relatively stiff adhesive. The obtained FEM model is then used to study the influence of geometrical parameters, such as the connection's diameter and glass thickness, and material parameters, such as the adhesive modulus of elasticity, on the mechanical behaviour of adhesive point-fixings under uniaxial load. The maximal occurring stresses in the glass panel and adhesive layer will increase with a decrease of the connector
\end{abstract}

\section{J. Dispersyn ( $\square)$}

Ghent University, Ghent, East-Flanders, Belgium

e-mail: jonas.dispersyn@ugent.be

Jan Belis

Department of Structural Engineering, Ghent University,

Ghent, Belgium diameter, the glass thickness and adhesive thickness, and with an increase of the adhesive stiffness. Furthermore, the maximal deformation of the glass panel can be reduced by increasing the glass thickness and adhesive stiffness, and by decreasing the connection diameter and the adhesive thickness.

Keywords Adhesive point-fixing - Axial loading · Numerical analyse

\section{Introduction}

The use of glass as a structural material has drastically increased the demand for architectural transparency. However, the connections between the structural glass and the underlying structure still represent one of the most critical aspects. Traditional systems to connect glass to the supporting substructure consist of linear supports. By using such systems, the transparency of the facade is highly reduced (Dodd 1997; Haldimann et al. 2008). In contrast, the overall transparency improves significantly by using so-called point-fixings (Vyzantiadou and Avdelas 2004; Siebert and Herrmann 2010). Bolted point-fixings are widely used in facades and canopies, as depicted in Fig. 1. These fixings typically consist of locally installed metal pieces, of limited size, connecting the glass elements to the structure using bolts through the glass. This requires the glass panel to be drilled in corner or edge zones, tempered and bolted (Siebert 2006). 
Fig. 1 Examples of bolted point-fixings used in a a façade for an elevator in Tampere, Finland and in $\mathbf{b}$ a canopy at the train station Sint-Pieters in Ghent, Belgium
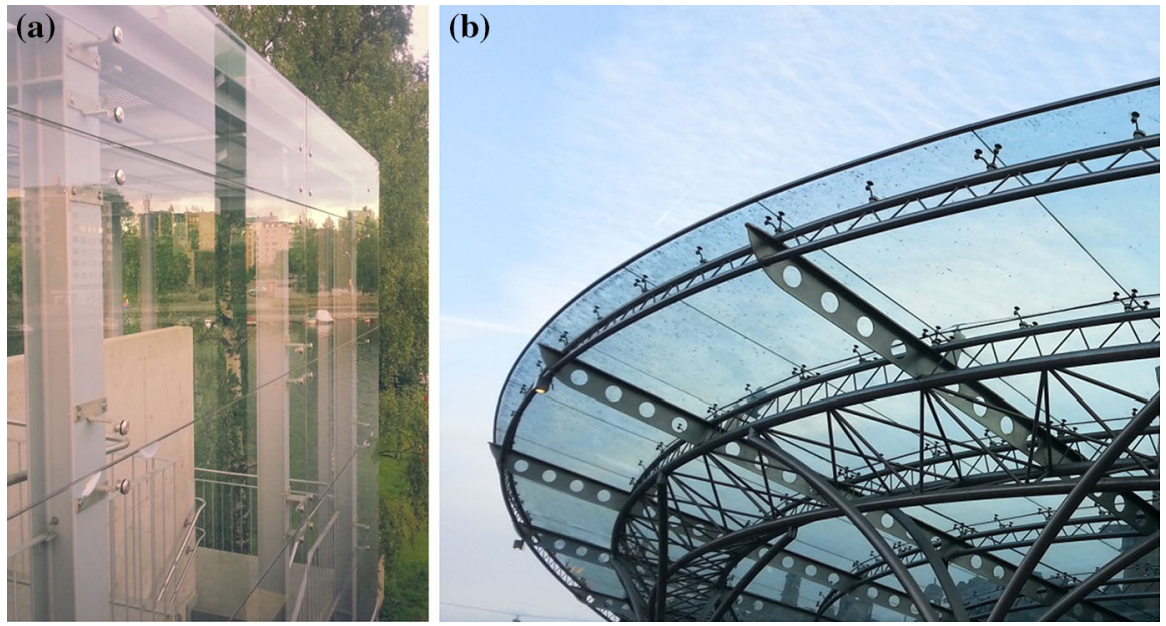

Despite the widespread use of bolted point-fixings, a major disadvantage of this type of connections is the significant weakening by the drilling process at the holes edges, which is where high stress peaks occur due to the transfer of forces by contact between metal and glass (Maniatis 2006; Beyer 2007; Feldmann et al. 2008; Overend 2005; Mocibob and Belis 2010). Due to the high stress concentrations at the borehole, tempered glass must be used. The use of adhesive connections avoids these stress concentrations because the glass is directly bonded to the metal connector. Indeed, adhesive joints reduce high stress peaks by spreading the force over a larger area (Weller and Tasche 2005; Sitte et al. 2011; Overend 2013; Santarsiero et al. 2013; Dispersyn et al. 2014a). However, the mechanical behaviour of adhesive point-fixings has not been extensively investigated yet. Also the studies that have been performed on adhesive point-fixings focus mainly on the adhesive bond between the glass and metal connector by supporting the glass panel right next to the connector (Weller and Tasche 2005; Bues et al. 2009; Sitte et al. 2011; Santarsiero et al. 2013). The experiments in these studies neglect the deformation of the glass panel, which does not correspond to reality. Indeed, the deformation of the glass will cause large stress concentrations in the adhesive layer.

In this work the connection is studied by supporting the glass panel at a circumference equal to 6 times the diameter of the connection. To gain a validated model, the experiments are performed with three different diameters $(30,50$ and $70 \mathrm{~mm})$ and three different glass thicknesses $(4,10$ and $19 \mathrm{~mm})$. The used adhesive is a relatively stiff two-component epoxy. The experimental and numerical test set-up is described in Sect. 2. For the validation, the strains at three different distances from the centre of the glass plate are measured using strain gauges. The comparison between the experimental and numerical values is given and discussed in Sect. 3. In Sect. 4, the obtained finite element method (FEM) model is then used to study the influence of geometrical parameters, such as the connection's diameter and glass thickness, and material parameters, such as the adhesive modulus of elasticity, on the mechanical behaviour of adhesive point-fixings under uniaxial load. Apart from the use of adhesive point-fixings, the experimental investigation of the entire connection is innovative considering that previous experiments on adhesive point-fixings have been mostly performed on only the adhesive layer, without bringing the influence of the stiffness of the glass panel into account. However, the glass deformation is only partially taken into account since local glass non-symmetric curvatures are not represented by the axial-symmetric boundary condition.

\section{Materials and methods}

The numerical model is based on the method of superposition of local and global components, i.e. the SLGmethod, developed by Beyer (2007). This method is already known from beam theory, in which complex structures are divided into global and local components. Based on the principle of the Saint-Venant, Beyer assumes that changing geometrical characteristics of the point-fixing have only an influence on the stress distribution in in a local region around the joints, while 
Table 1 Test combinations

\begin{tabular}{lcccc}
\hline \multicolumn{2}{l}{ Glass thickness (mm) } & & & \\
\hline 4 & 10 & 19 & 30 & Connector diameter (mm) \\
\hline$X$ & $X$ & 50 & 70 \\
\hline
\end{tabular}

the influences decrease further away from the connection. This principle allows to separate the entirety from the connections (the global component), and the connections from the entirety (the local component).

The entire glass plate is modelled in a 2-D FEA as the global component in which the point-fixings are represented by springs with a certain stiffness given in datasheets. Using this model the stresses at the boundary between the global and local component can be determined, referred to as the global stress. Furthermore the support reactions of the point fittings $(\mathrm{N}, \mathrm{Q}$, M) are determined.

For the local design, the glass plate around the borehole and the connection are modelled in detail representing the local component. The diameter of the local component $\phi_{\text {loc }}$ for bolted point-fixings is determined to be at least six times the diameter of the borehole $\phi_{\text {hole }}$, as is expressed in Eq. 1.

$\phi_{\text {loc }} \geq 6 \cdot \phi_{\text {hole }}$

By applying the reaction forces and moments on the connection derived from the global component, the reaction stresses $\sigma_{\mathrm{Fz}}, \sigma_{\mathrm{Fxy}}$ and $\sigma_{\mathrm{M}}$ are determined. The sum of these stresses and the global stresses must be less than the critical stress $\sigma_{\mathrm{R}}$ for the glass plate according to Eq. 2.

$\sigma_{F z}+\sigma_{F x y}+\sigma_{M}+\mathrm{k} \cdot \sigma_{\text {globaal }} \leq \sigma_{R}$

Recent research has shown that the method is also applicable for adhesive point-fixings (Dispersyn et al. 2014b). The superposition of global and local components means that the investigation of glass plates supported by adhesive point-fixings can be simplified to the investigation of the local area and a simple global model. By supporting the glass plate in the local component along a circumference with a diameter equal to six times the connector diameter, the deformation of the glass panel is also taken into account in the local area. Taking into consideration, the remark that local glass non-symmetric curvatures are not represented by the axial-symmetric boundary condition in the local component. The aim of this paper is to validate and investigate the numerical local component.

\subsection{Test specimens and materials}

Research on bolted point-fixings and adhesive pointfixings demonstrated that many parameters have an influence on the stress distributions and strength of adhesive point-fixings, such as the diameter of the connection, the thickness of the glass, the tempering process, the shape of the fitting, the type of adhesive, environmental parameters, the spew fillet etc. (Tsai 1995; Siebert 2006; Bues et al. 2009; Mocibob and Belis 2010; Nielsen et al. 2010; Santarsiero et al. 2013). To obtain a completed validated numerical model, experiments are conducted with different geometrical parameters and material characterisation. Three different diameters are used $(30,50$ and $70 \mathrm{~mm})$ and three different glass thicknesses (4, 10 and $19 \mathrm{~mm}$ ). Due to the economic reasons a fractional factorial design was preferred. The combinations of the two parameters are listed in Table 1, where the combination of $10 \mathrm{~mm}$ glass thickness and $50 \mathrm{~mm}$ connector diameter is taken as the reference case.

In the experiments, the circumference is simply supported. The support consists of a steel plate with an opening that has a diameter equal to six times the diameter of the fitting. The width and length of the glass plate are seven times the fitting diameter. So for example the configuration with a $50 \mathrm{~mm}$ connector diameter results in a glass panel of $350 \mathrm{~mm} \times 350 \mathrm{~mm}$ which is simply supported along a circumference with a diameter of $300 \mathrm{~mm}$. For the validation, the strain at three different distances from the centre on the glass plate was measured using strain gauges. The positions of the strain gauges are determined by means of a preliminary FEM model. The dimensions of the glass plate, the circumference of the support and the positions of the strain 
Fig. 2 Dimensions of the glass plates with position of the strain gauges for a connector diameter of 30 , 50 and $70 \mathrm{~mm}$. All distances are in $\mathrm{mm}$

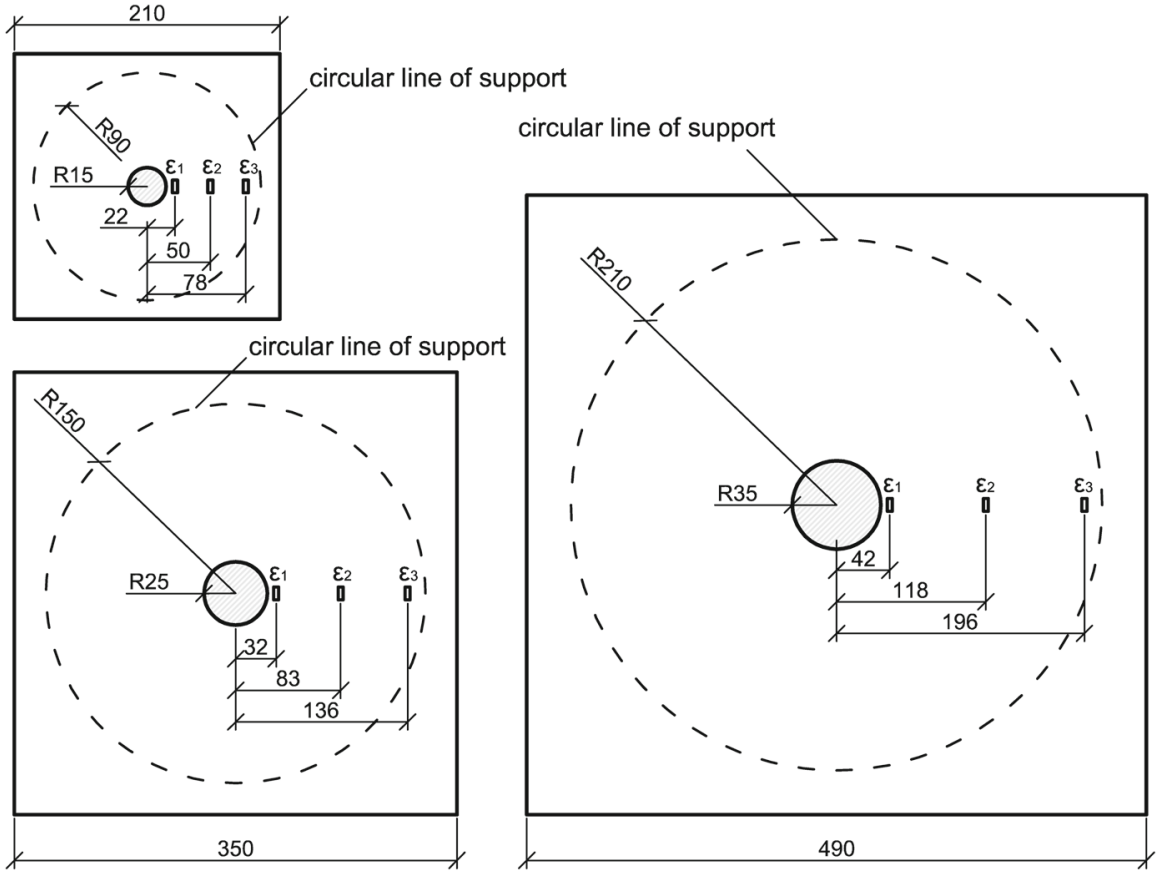

gauges are illustrated in Fig 2. Due to economic reasons the stresses of only four out of ten test specimens were completely determined, where the six remaining specimens were used to measure the variation between the specimens and measured only the strain $\varepsilon_{2}$. At the same three distances from the centre, denoted as $\mathrm{U}_{1}$, $\mathrm{U}_{2}$ and $\mathrm{U}_{3}$, the deflection of the glass is measured by using linear variable differential transducers (LVDT). However, due to practical constraints, for the configuration with a connector diameter of $30 \mathrm{~mm}_{1}$ is measured at a distance of $30 \mathrm{~mm}$ from the centre and for the configuration with a connector diameter of $70 \mathrm{~mm}$ $\mathrm{U}_{3}$ at a distance of $172.5 \mathrm{~mm}$. A certain scatter of the experimental results is expected due to small imperfections that can rise during the production process of the connector and the glass and also during the fabrication process of the connection.

There are many types of adhesives on the market varying from relatively flexible and low-strength adhesives, such as silicones, to relatively stiff and high-strength adhesives, such as epoxies and acrylates. The latter are non-toughened, thermosetting adhesives. These kinds of adhesives are usually brittle materials that will fail at relatively small strains. These materials mostly yield sufficient accuracy when modelled with linear elastic behaviour, as long as the deformations and temperature are not too high. In contrast, other commer- cial adhesives are rubber toughened, such as silicones and MS-polymers. Due to the rubber phase that occurs here, relatively large strains $(>5 \%)$ can occur with large deformation prior to failure. One adhesive is selected, namely a relatively stiff and high-strength adhesive. An extensive experimental programme on adhesives for structural applications with glass and metal connectors has been performed by researchers of Ghent University and Delft University of Technology to help designers select potential adhesives based on specific environmental exposures and loading conditions. The project yielded an adhesive selection tool based on performance criteria (Belis et al. 2011a,b).The selection of the adhesive is made based on this research. The selected adhesive is the $3 \mathrm{M}$ Scotch Weld $9323 \mathrm{~B} / \mathrm{A}$, is a two component epoxy paste adhesive which cures in 14 days at room temperature to form a tough, impact resistant structural bond. It has an excellent adhesion to a wide variety of substrates such as metals, glass, ceramics and plastics. Once cured it provides high shear and peel strength over a wide temperature (3M 2010). In future research also a more flexible adhesive will be investigated.

The optimum adhesive thickness of the 2c-epoxy $3 \mathrm{M}$ Scotch Weld $9323 \mathrm{~B} / \mathrm{A}$ is equal to $0.2 \mathrm{~mm}$ according to the technical data sheet of the producer (3M 2010). The thicknesses were carefully ensured by the use of 
Fig. 3 Example of the bracket with a connector of $\varnothing 70 \mathrm{~mm}$ and a detail of the $0.2 \mathrm{~mm}$ layer thickness
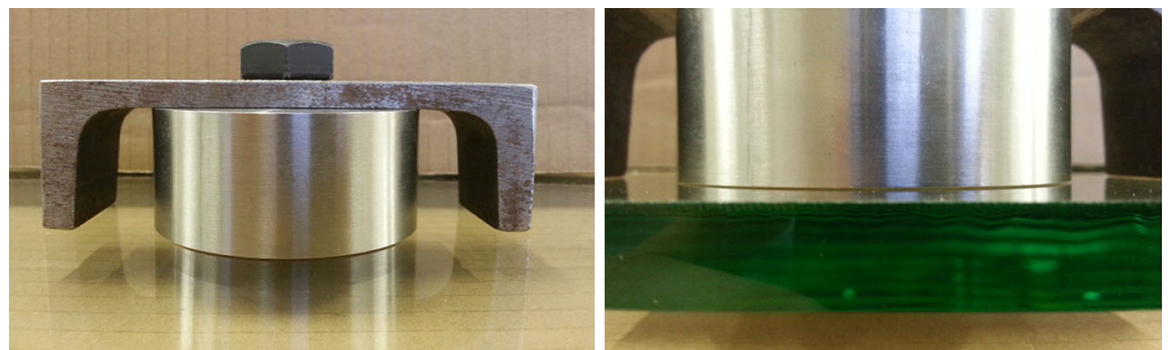

high precision milled steel brackets. These brackets ensured that the connector was always $0.2 \mathrm{~mm}$ above the glass panel. An example of this bracket is illustrated in Fig. 3. Before applying the adhesive, the glass panel and connector were degreased thoroughly. After applying the adhesive on the connector, the connector and the bracket were placed on the air side of the glass panel and excess adhesive was removed. Of every configuration ten specimens are fabricated and tested, 5 configurations give a total of 50 experimental specimens. To avoid climatic influences during the curing process the specimens were stored for four weeks in a climatic chamber at a constant temperature of $21^{\circ} \mathrm{C}$ and a relative humidity of $45 \%$ without any UVradiation.

The glass transition temperature of the selected adhesive is determined with a dynamic mechanical thermal analysis (DMTA) and a differential scanning calorimetry (DSC). The former gives a value of $74,58^{\circ} \mathrm{C}$ for the glass transition temperature and the latter a value of $74.6^{\circ} \mathrm{C}$. Since the working temperature is lower than the glass transition temperature for the stiff 2c-epoxy 3M Scotch Weld $9323 \mathrm{~B} / \mathrm{A}$, the adhesive is assumed to be a glassy adhesive and to behave linear elastically. When a linear elastic material is deformed by a load, the material will take back its original form after reloading it, following the same path as when it was loaded. This behaviour can be characterised by the Young's modulus. Often is also the Poisson's ratio needed to obtain a correct material model. Since the material model will be more accurate if experimental data is obtained for different load directions, the calibration of the material model was performed with the experimental data obtained from uniaxial tensile, compressive and shear experiments (Sasso et al. 2008; Stumpf and Marczak 2010). All these small-scale experiments were performed on a Zwick/Roell $10 \mathrm{kN}$ ProLine testing machine with a load cell of $10 \mathrm{kN}$. All test specimens were stored after curing for a time period
Table 2 Material properties of the adherents

\begin{tabular}{lll}
\hline & $\begin{array}{c}\text { Young's mod- } \\
\text { ulus } E(\mathrm{MPa})\end{array}$ & $\begin{array}{l}\text { Poisson's } \\
\text { ratio } v(-)\end{array}$ \\
\hline $\begin{array}{l}\text { Stainless steel } \\
\text { EN10088-1 1.4404 }\end{array}$ & 195,000 & 0.30 \\
Annealed float glass & 70,000 & 0.23 \\
\hline
\end{tabular}

of 4 weeks at a constant temperature of $21^{\circ} \mathrm{C}$ and a relative humidity of $45 \%$ without any UV-radiation in a climatic chamber. Dumbbells, solid cylinders and $\mathrm{V}$-notched beam test specimens have been made. Local deformations of the test specimens have been measured through three-dimensional digital image correlation (DIC). The comparison between the data from the test machine and the DIC-output revealed major differences between the measured deformations. This confirms that the use of DIC is needed to accurately measure the occurring strains during the tensile, compressive and shear tests. From these small-scale tests the material characteristics are determined and are equal to $2267.37 \mathrm{MPa}$ and 0.39 for the Young's modulus and the Poisson's ratio, respectively. In tension, these smallscale specimens failed brittle at $34 \mathrm{MPa}$ and in shear at $22 \mathrm{MPa}$.

The other two materials of the adhesive point-fixings are the adherents. For the metal a cylinder was made of stainless steel EN 10088-1 1.4404 (AISI 316L), a common used type of stainless steel, and the glass was annealed soda-lime float glass. The adherents were modelled with linear elastic behaviour, using the material properties given in Table 2. The material properties of glass and stainless steel are derived from literature (Outeiro et al. 2006; Haldimann et al. 2008).

\subsection{Test method}

As depicted in Fig. 1 adhesive point-fixings can be used for supporting glass facades or glass canopies. 
Fig. 4 Examples of the different types of SSGS, based on ETAG 002 (2012)
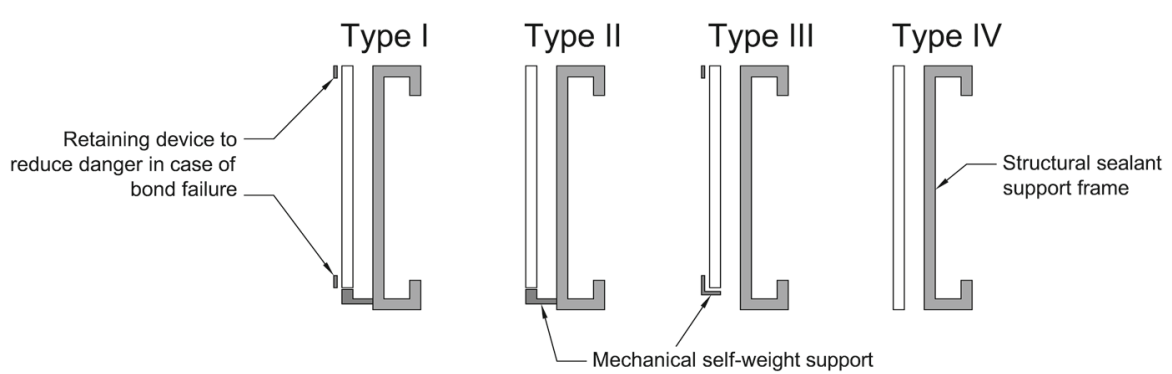

In the case of glass canopies, the supports can be placed underneath the glass panel so the connection is loaded under pressure by the dead load of the glass panel and possibly under tension by wind suction. However, when the support is placed on top of the glass panel, the connection will be almost continuously loaded in tension by the dead load of the glass panel. Since compressive forces rarely cause a problem for the adhesive layer, the tensile forces will be the determining factor for the design of adhesive point-fixings in canopy applications. This also applies to facades, as mechanical self-weight supports are mostly described for Structural Sealant Glazing Systems (SSGS) according to the ETAG 002 as depicted in Type I and II in Fig. 4. With mechanical self-weight supports the connection will only be loaded by horizontal actions and again the tensile forces will be the determining factor for the design. These remarks considered, only tensile forces are considered in this paper since independent of the application, tensile forces will be the most determining factor. Consequently, the experiments will be used to validate the factor $\sigma_{\mathrm{Fz}}$ in Eq. 2.

As stated above, the local component is the glass plate with a diameter six times the diameter of the connector. In the experiments, the circumference was simply supported and the fitting was loaded with a tensile force till failure. To test the specimens under uniaxial tension, a special test frame was fabricated. The support consisted of a steel plate with an opening that had a diameter equal to six times the diameter of the fitting. A visualization of the test frame for the reference configuration is depicted in Fig. 5. The tensile tests were performed on a universal electro-mechanic test machine Instron 5800R (frame 4505 retrofitted with a digital controller 8800). A load cell of 10 or $100 \mathrm{kN}$ was used and the displacement of the crosshead and the load was measured.

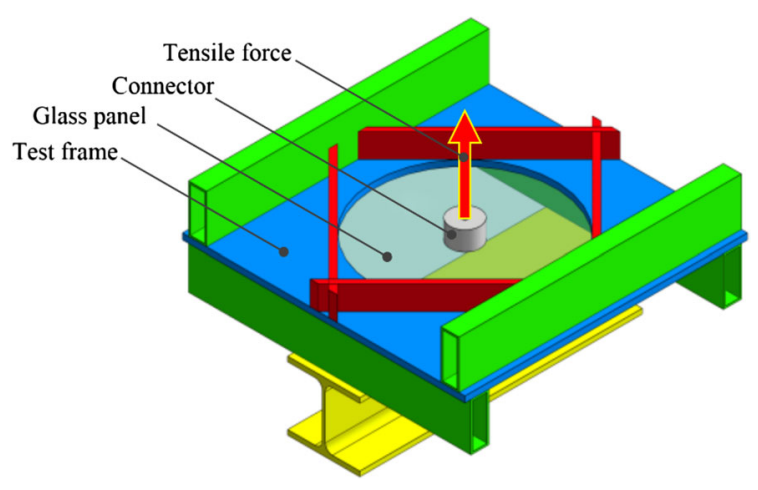

Fig. 5 Test frame for uniaxial tensile tests for the reference configuration, i.e. connector diameter of $50 \mathrm{~mm}$ and a glass thickness of $10 \mathrm{~mm}$

\subsection{Numerical model}

The finite element software Abaqus ${ }^{\circledR}$ was used to build a three-dimensional finite element model and to numerically analyse the connection. Due to symmetry only a quarter of the glass plate was numerically modelled. Extra attention was paid to the location around the connector where refinement of the mesh pattern was introduced since stress concentrations were expected to occur here. To avoid mesh singularities in the centre of the circular connector a square mesh pattern was inserted inside the circular pattern. The mesh refinement around the connector and the square pattern are illustrated in Fig. 6. In this figure also the path along the $\mathrm{x}$-axis is depicted where the nominal strains perpendicular to this path are determined. As strain gauges direct measure the deformation as the change in length to length, the nominal strain in Abaqus ${ }^{\circledR}$ is used for the validation since the nominal strain is defined in Abaqus ${ }^{\circledR}$ as the ratio of change in length to length in the reference configuration, i.e. the same as the measured strain. Along the circular line of support, the upward displacement is prevented as the boundary condition for $\mathrm{U}_{z}$ is set to zero. 
Fig. 6 Detail of the refined mesh pattern at the centre for the reference configuration

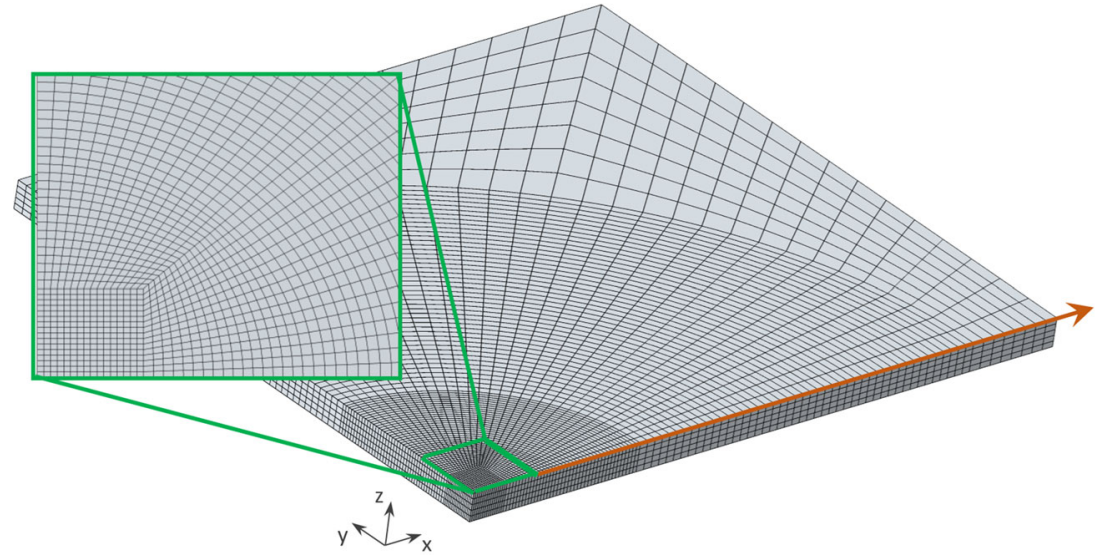

Table 3 Element size and type for the three materials

\begin{tabular}{lllll}
\hline Material & Element type & \multicolumn{3}{l}{ Element size $(\mathrm{mm})$} \\
\cline { 3 - 5 } & & $\emptyset 30 \mathrm{~mm}$ & $\varnothing 50 \mathrm{~mm}$ & $\varnothing 70 \mathrm{~mm}$ \\
\hline Glass & C3D20 & 0.491 & 0.818 & 1.145 \\
Steel & C3D20 & 0.491 & 0.818 & 1.145 \\
2c-epoxy 3M & C3D20 & 0.123 & 0.205 & 0.286 \\
$\quad$ Scotch & & & & \\
Weld 9323 & & & & \\
B/A & & & & \\
& & &
\end{tabular}

The adhesive layer is connected by means of a tieconstraint to the glass and the metal connector. The tieconstraint between glass-adhesive and metal-adhesive is modelled as a master-slave surface, with the adhesive layer each time as the slave surface. Surface-to-surface is selected as discretization method and for the position tolerance method Abaqus ${ }^{\circledR}$ determines the nodes to be tied using the default position tolerance. This kind of constraint specifies that the mesh size of the slave surface has to be smaller than the mesh size of the master surface. A convergence study demonstrated that the best results are obtained when the mesh of the adhesive layer is three times finer than the glass and steel mesh. This refinement also allowed to investigate thoughtfully the stresses that occur in the adhesive layer.

A convergence study was performed to determine which element type and element size gives the most accurate results with the lowest CPU-time. The results of the convergence study are summarized in Table 3. Here, 20-nodes quadratic brick elements were used. The element size is the size of one element along the circumference of the connection. The mesh sizes given in Table 3 give 24 elements along the quarter circum- ference of the connection for the glass and the steel and 98 elements along the quarter circumference for the adhesive layer. Abaqus ${ }^{\circledR}$ will account for geometric nonlinearity in every step of the static step-by-step numerical analyse

\section{Results and discussion}

\subsection{Experimental results}

The failure mechanisms of the test samples can be divided into two categories: glass failure and cohesive failure. An example of glass failure is depicted in Fig. 7a. A thin film of epoxy remained on the glass when cohesive failure occurred; this phenomenon is also known as the thin layer cohesive failure pattern (Lee et al. 2009). This thin film is visible in Fig. 7b on the glass panel.

The maximum tensile forces corresponding to cohesive failure for all configurations are depicted in Fig. 8, where the letter $t$ is used to indicate the glass thickness and the letter $D$ for the connector diameter. For example, t19 D30 refers to a specimen with a glass thickness of $19 \mathrm{~mm}$ and a connector diameter of $30 \mathrm{~mm}$. Tensile forces up to $15 \mathrm{kN}$ are reached. The high failure tensile forces prove that adhesive point-fixings are indeed a good alternative for the connection of glass panels to the underlying structure. The adhesive ensures that no boreholes are needed, which gives stronger and visually more appealing glass panels. The thickness of the glass has a bigger influence on the strength than the diameter. Indeed, the thin glass plates deformed much more than the thicker glass plates, and the corresponding curvature under the fitting introduced stress concentrations 
Fig. 7 Example of a glass failure and $\mathbf{b}$ thin layer cohesive failure pattern
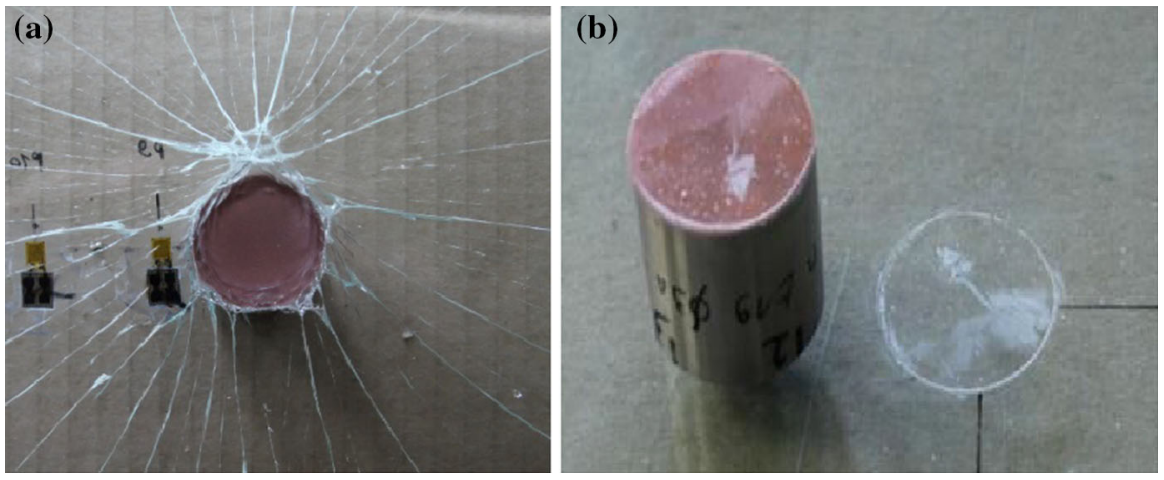

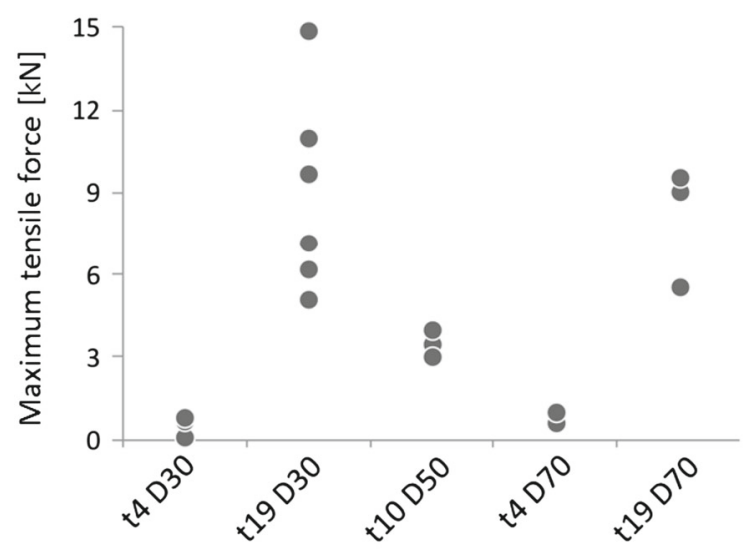

Test specimen configuration

Fig. 8 Maximum tensile forces corresponding to cohesive failure

at the edge of the fitting. These stress concentrations caused the connection to fail faster compared to thicker plates. The influence of the glass thickness will be studied in the parametric study in Sect. 4. Thicker glass plates were so stiff that the glass plate stayed relatively straight during the test, causing almost only uniaxial tensile in the adhesive layer. From this it can be concluded that the glass thickness is more determinative for rather stiff adhesives. The scatter of the experimental results is probably due to small imperfections that occurred during the fabrication process of the connection. Despite the fact that the thickness of the adhesive has been carefully and with high precision ensured, very small differences in thickness will always occur. And these differences have a major influence on the strength of the connection. Also the two components of the adhesive are mixed manually to an homogenous paste. Small variations in the homogeneity will also have an influence on the strength.
Table 4 Minimal tensile force for each configuration.

\begin{tabular}{ll}
\hline $\begin{array}{l}\text { Specimen } \\
\text { configuration }\end{array}$ & $\begin{array}{l}\text { Minimal } \\
\text { tensile force }(\mathrm{kN})\end{array}$ \\
\hline t4 D30 & 0.6 \\
t4 D70 & 0.5 \\
t10 D50 & 2.9 \\
t19 D30 & 4.9 \\
t19 D70 & 4.7 \\
\hline
\end{tabular}

\subsection{Validation of numerical results}

As mentioned above, three strain gauges are used to measure the occurring stresses in the glass panel together with the displacement of the glass panel at three locations. These strain gauges and deformations form one path. The obtained experimental results are used to validate the developed numerical model. The comparison between the experimental and numerical values is performed for the five geometrical configurations. The numerical nominal strains NE22 and vertical displacements U33 are obtained for the predefined path (Fig. 6). In Abaqus ${ }^{\circledR} 11,22$ and 33 are the components in the $\mathrm{x}-, \mathrm{y}$ - and $\mathrm{z}$-direction, for example is NE22 the nominal strain in y-direction. The applied tensile force is the minimal force that is obtained for each configuration regardless of the failure mode. The applied tensile forces are summarized in Table 4 for each configuration. The comparison for the numerical strains NE22 and the strains measured during the experiments are illustrated in Fig. 9 for the specimens with the relatively stiff adhesive 3M Scotch Weld 9323 B/A (represented as the abbreviation $3 \mathrm{M}$ ). The dots represent the experimentally measured strains and the full line is the strain NE22 from the finite element model. The dotted lines represent the edge of the connection and the support, 

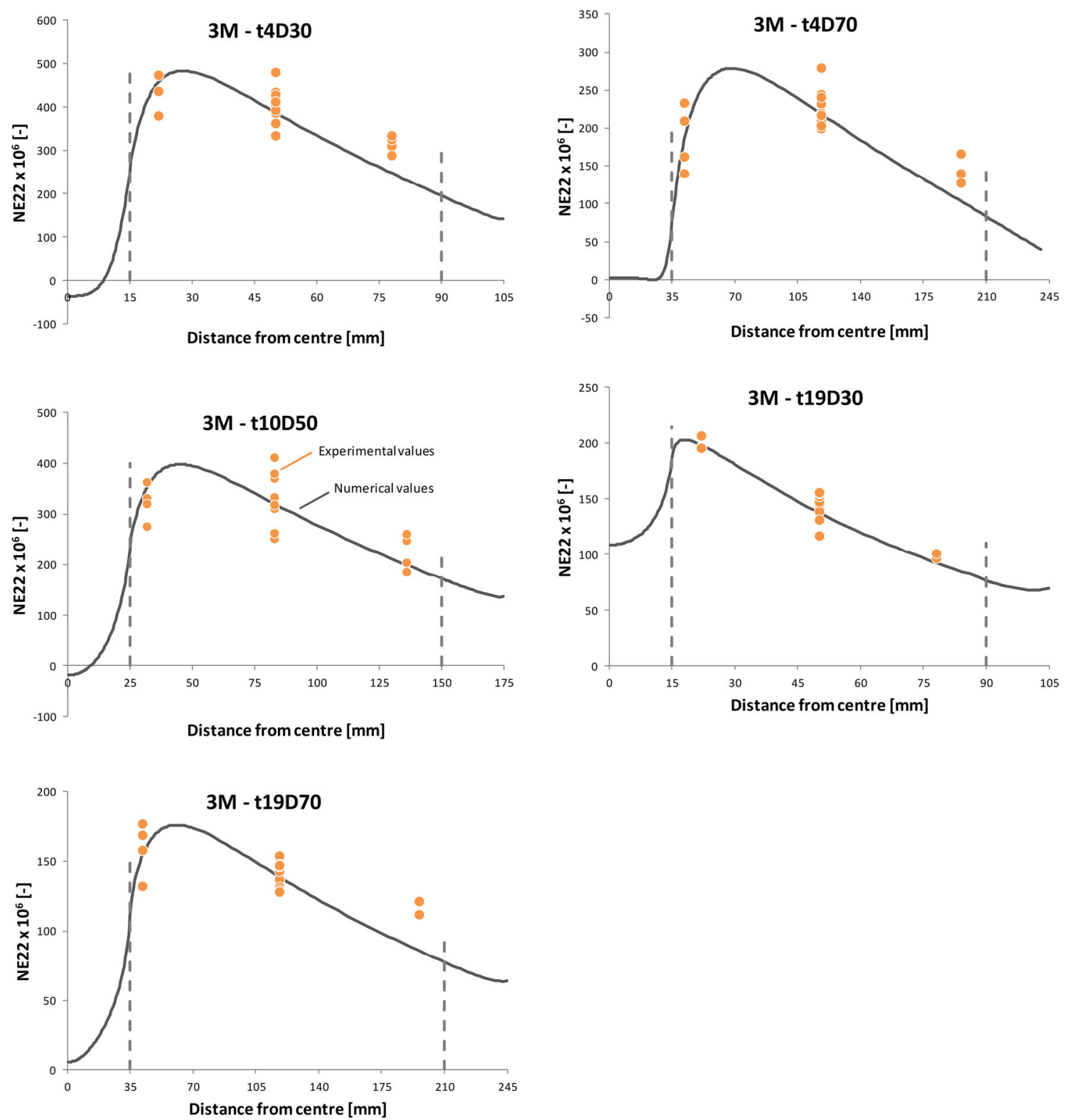

Fig. 9 Validation of the numerical strain NE22 of the local model for 3M Scotch Weld 9323 B/A

respectively. Despite of a certain scatter of the experimental result, a good agreement between the numerical and experimental results is achieved. From this graphs, one can conclude that the glass deformations under the connection are impeded by the adhesive. The strains even become zero or smaller for most configurations, only with a glass thickness of $19 \mathrm{~mm}$ and a connector diameter of $30 \mathrm{~mm}$ larger strains are obtained in the centre of the glass panel. This phenomenon influences the position of the maximal strain and, consequently, the position of the maximal stresses. As can be seen in Fig. 9, the location of maximal strain is outside the connection. This was also observed by the location of the crack initiation when the specimens fail due to glass failure. The crack initiation was situated close to the connection as depicted in Figs. 7 and 10

As mentioned above, also the displacements are measured and can be compared with the numerical 


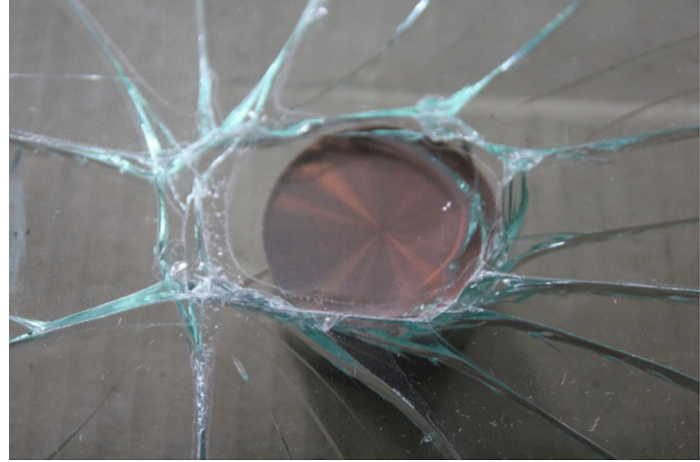

Fig. 10 Location of the crack initiation for the specimen configuration t10D50

deformation of the glass panel. The applied tensile force is the same as for the validation of the strains (Table 4). The comparison for the numerical deformation U33 and the displacements measured during the experiments are illustrated in Fig. 11. The dots represent again the experimental measured deformations and the full line is the deformation U33 from the finite element model. The scatter of the experimental values is larger compared to the experimental values of the
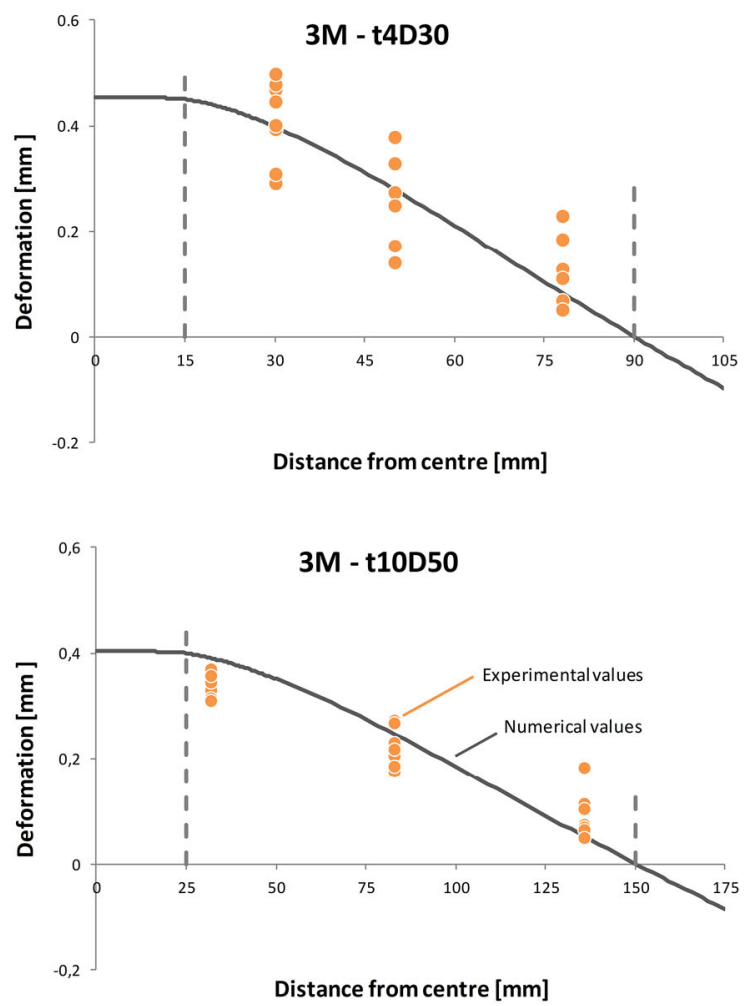

strains. From the FEA, the maximal deformation of the specimens with a glass thickness of $19 \mathrm{~mm}$ was 0.043 and $0.193 \mathrm{~mm}$ for a connector diameter of 30 and 70 $\mathrm{mm}$, respectively. These values are too small to measure properly with LVDT's and are therefore not depicted. For the other specimens, the glass panel will remain straight under the connection and will so introduce a bending point outside the connection, at the location of maximal strain. Logically, the thinner the glass panel the larger the deformations.

The mean experimental values for the strains with their standard deviation (SD) is given in Tables 5 and in 6 for the deformations, also the numerical values are given. For the strains, the SD is under $15 \%$ for every value except for $\varepsilon_{1}$ for specimen t4D70. However, in Fig. 9 the numerical strain curve is very steep at the position of $\varepsilon_{1}$ for t4D70, so a small difference in location of the strain gauge has a large influence on the value of the strain. Based on the comparison between the numerical and experimental values for the strains and deformations, it can be concluded that the FEM model is hereby validated.

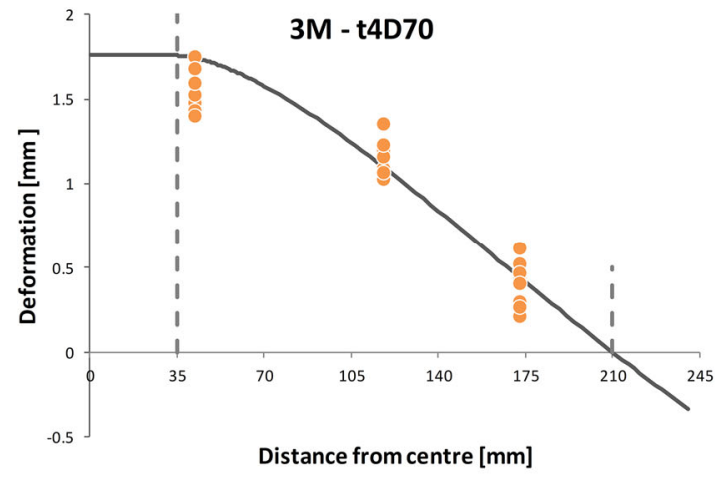

Fig. 11 Validation of the numerical deformation U33 of the local model for $3 \mathrm{M}$ Scotch Weld $9323 \mathrm{~B} / \mathrm{A}$ 
Table 5 The mean values for the experimental strains with their standard deviation for each specimen and their numerical value

\begin{tabular}{|c|c|c|c|c|c|c|}
\hline \multirow[t]{2}{*}{ Specimen } & \multicolumn{2}{|l|}{$\varepsilon_{1} \times 10^{6}(-)$} & \multicolumn{2}{|l|}{$\varepsilon_{2} \times 10^{6}(-)$} & \multicolumn{2}{|l|}{$\varepsilon_{3} \times 10^{6}(-)$} \\
\hline & Exp. & Num. & Exp. & Num. & Exp. & Num. \\
\hline $3 \mathrm{M} \mathrm{t4D} 30$ & $431.14( \pm 46.67)$ & 458.15 & $404.54( \pm 40.42)$ & 388.24 & $315.80( \pm 19.76)$ & 248.34 \\
\hline $3 \mathrm{M} \mathrm{t4D70}$ & $186.42( \pm 42.57)$ & 184.79 & $226.66( \pm 23.59)$ & 218.85 & $144.84( \pm 19.46)$ & 103.16 \\
\hline 3M t10D50 & $322.00( \pm 36.19)$ & 352.48 & $342.46( \pm 52.12)$ & 320.45 & $223.96( \pm 35.23)$ & 199.98 \\
\hline 3M t19D30 & $199.06( \pm 5.52)$ & 198.40 & $145.49( \pm 12.58)$ & 137.98 & $98.64( \pm 2.00)$ & 92.53 \\
\hline 3M t19D70 & $159.18( \pm 19.61)$ & 154.19 & $141.38( \pm 9.22)$ & 139.01 & $118.18( \pm 5.30)$ & 85.75 \\
\hline
\end{tabular}

Table 6 The mean values for the experimental deformations with their standard deviation for each specimen and their numerical value

\begin{tabular}{|c|c|c|c|c|c|c|}
\hline \multirow[t]{2}{*}{ Specimen } & \multicolumn{2}{|l|}{$\mathrm{U}_{1}(\mathrm{~mm})$} & \multicolumn{2}{|l|}{$\mathrm{U}_{2}(\mathrm{~mm})$} & \multicolumn{2}{|l|}{$\mathrm{U}_{3}(\mathrm{~mm})$} \\
\hline & Exp. & Num. & Exp. & Num. & Exp. & Num. \\
\hline $3 \mathrm{M} \mathrm{t} 4 \mathrm{D} 30$ & $0.399( \pm 0.082)$ & 0.399 & $0.258( \pm 0.090)$ & 0.280 & $0.143( \pm 0.073)$ & 0.083 \\
\hline 3M t4D70 & $1.541( \pm 0.115)$ & 1.743 & $1.161( \pm 0.105)$ & 1.099 & $0.417( \pm 0.131)$ & 0.446 \\
\hline $3 \mathrm{M} \mathrm{t10D50}$ & $0.334( \pm 0.022)$ & 0.391 & $0.222( \pm 0.034)$ & 0.247 & $0.090( \pm 0.043)$ & 0.051 \\
\hline
\end{tabular}

Table 7 The investigated parameters and the corresponding values

\begin{tabular}{lll}
\hline Parameter & Symbol and unit & Values \\
\hline Connector diameter & $\varnothing(\mathrm{mm})$ & $15,30,50,70,100$ \\
Glass thickness & $\mathrm{t}_{\text {glass }}(\mathrm{mm})$ & $2,4,9,1215,19$ \\
Adhesive thickness & $\mathrm{t}_{\text {adhesive }}(\mathrm{mm})$ & $0.05,0.1,0.2,0.5,1$ \\
Adhesive Young's modulus & Eadhesive $_{(\mathrm{mm})}$ & $50,200,1000,2500,5000,10,000$ \\
Adhesive Poisson's ratio & $v_{\text {adhesive }}(-)$ & $0.35,0.37,0.39,0.41,0.43$ \\
\hline
\end{tabular}

\section{Parametric study}

The validated numerical model now enables to investigate more thoroughly the geometrical and material aspects of a point-fixing loaded in tension. In this paragraph, firstly the diameter of the connector $(D)$ is investigated together with the thickness of the glass $\left(t_{\text {glass }}\right)$. Next, the adhesive thickness ( $t_{\text {adhesive }}$ ) together with the young's modulus of the adhesive ( $\left.E_{\text {adhesive }}\right)$ and finally the influence of the Poisson ratio (vadhesive) is studied. The values for each parameter are summarized in Table 7. The maximal value of the maximal principal stress is obtained for the glass panel and the adhesive layer, separately. With these values the influence of each parameter is investigated. Indeed, the maximal principal stress is often used as a failure criterion for structural glass and adhesives (Haldimann et al. 2008; Crocombe et al. 1990; Clark and McGre- gor 1993; Dean et al. 2004; Christensen 2013). Also the maximal deflection of the glass panel is obtained. For the convenience in the parametrical study a Young's modulus of $2000 \mathrm{MPa}$ and a Poisson's ratio of 0.39 will be used to simulate a stiff adhesive. The applied force on the numerical model for the parametric study is always equal to $1 \mathrm{kN}$.

\subsection{Connector diameter and glass thickness}

The influence of the diameter of the connection is studied for values between 15 and $100 \mathrm{~mm}$, and the glass thickness varies between 2 and $19 \mathrm{~mm}$. As mentioned before, the stiff adhesive is modelled with a thickness of $0.2 \mathrm{~mm}$, a Young's modulus of $2000 \mathrm{MPa}$ and a Poisson's ratio of 0.39 . The maximal principal stress in the glass panel for the configurations for each stud- 


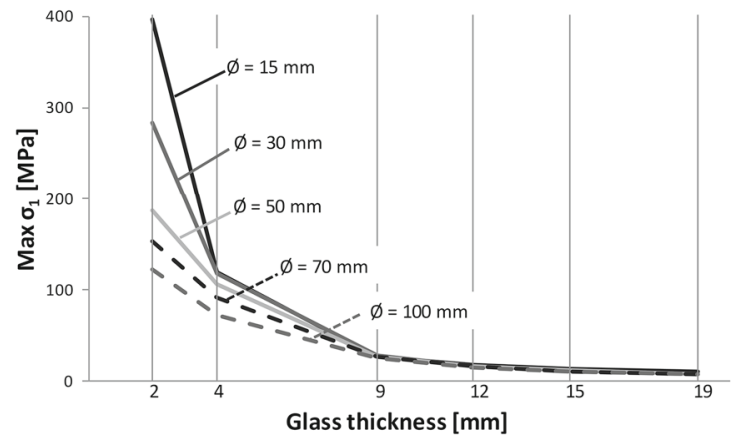

(a)

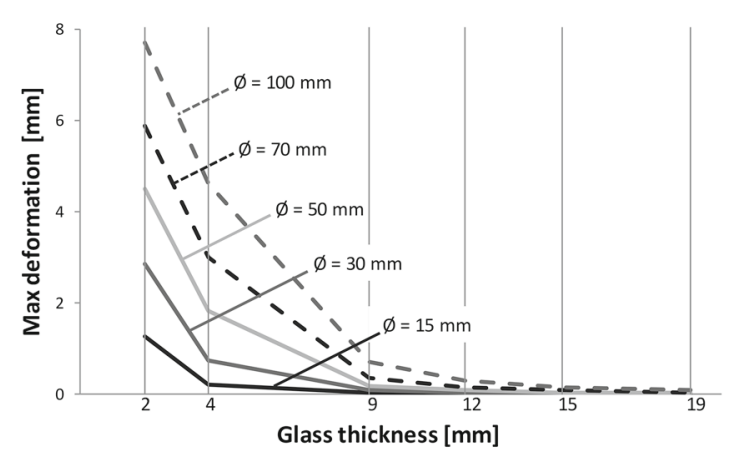

(c)

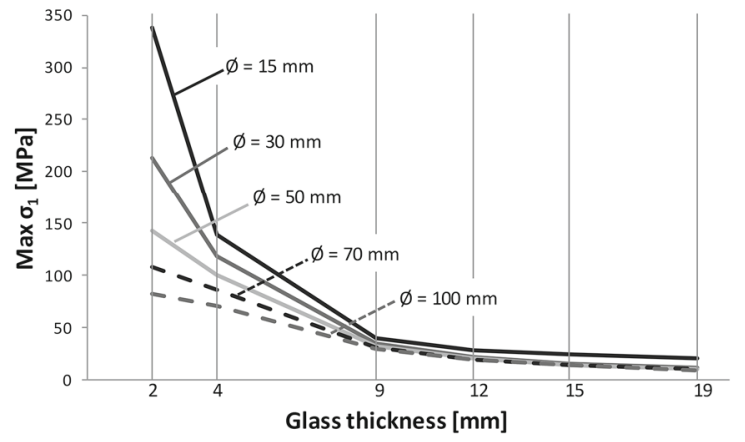

(b)

Fig. 12 Maximal value of the maximal principal stress in $\mathbf{a}$ the glass panel, $\mathbf{b}$ the adhesive layer and $\mathbf{c}$ the maximal deformation of the glass panel tin function of the glass thickness and connector diameter

ied connector diameter is depicted in Fig. 12a in function of each investigated glass thickness. An increasing diameter has a positive effect on the stresses. A larger diameter will support the glass panel over a larger surface, resulting in lower stresses. The maximal principal stress in the adhesive layer is given in Fig 12b. Also the maximal value for the maximal principal stress decreases with an increase of the connector diameter and glass thickness. This confirms the assumption that thin glass panels will give larger stress concentrations. The reduction in stress between 9 and $19 \mathrm{~mm}$ thick glass is an average factor of 3.5, while the used volume will only rise with a factor of 2.1 , so there is an economical benefit as well. The influence of the diameter will also reduce with larger glass thicknesses. However, specimens with a larger diameter will have a larger deflection, as is visualised in Fig. 12c. The decrease of stiffness of the glass panel is due to the increase of the size of the glass panel. Indeed, with the SLG-method the size of the glass panel depends on the diameter, i.e. the width and length of the glass panel is equal to seven times the connector diameter and the support diameter is equal to six times the connector diameter. When the glass panel would have a fixed geometry and support diameter, one would expect that the glass deformation would decrease with increase connector diameter. This was showed in the research of Dispersyn et al. (2015a), where a glass panel of 1 by $2 \mathrm{~m}$ supported by six adhesive point-fixings is investigated. Increasing the connector diameter resulted in a decrease of the maximal deflection of the glass panel. The increase in thickness of the glass will increase the moment of inertia of the glass panel. The increase of the rigidity of the panel will result in lower stresses and deformations (Dispersyn et al. 2015a).

\subsection{Adhesive thickness and Young's modulus}

Recent experimental research on local adhesive pointfixings has shown that the young's modulus of the adhesive has a significant influence (Dispersyn et al. 2015b). The values from Table 7 are applied on the 


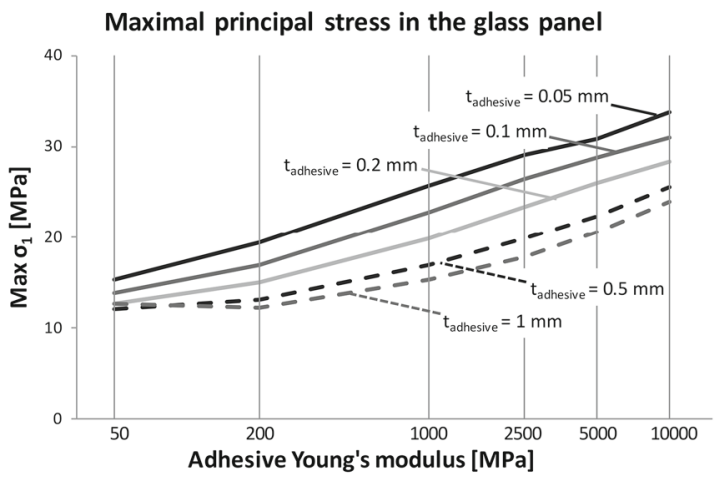

(a)

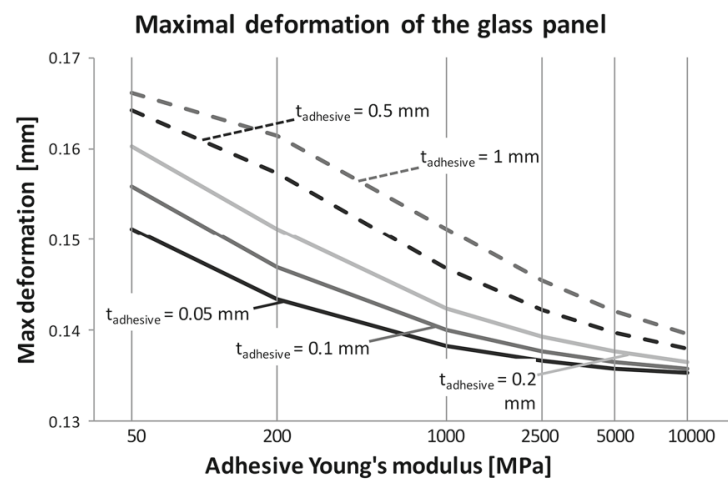

(c)

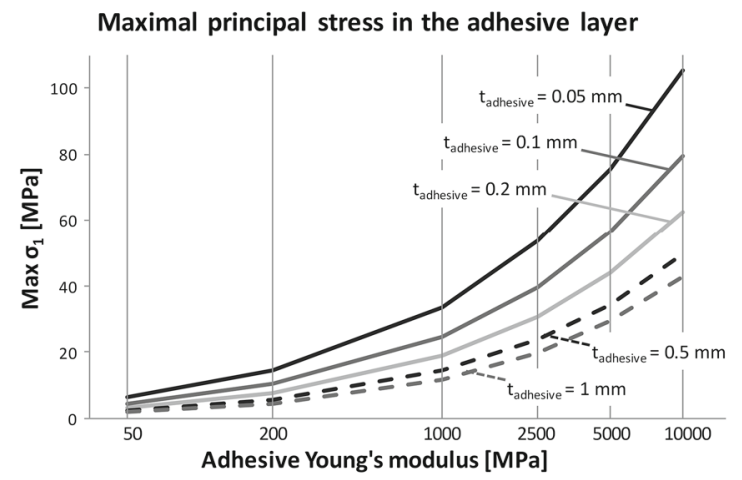

(b)

Fig. 13 Maximal value of the maximal principal stress in a the glass panel, $\mathbf{b}$ the adhesive layer and $\mathbf{c}$ the maximal deformation of the glass panel in function of the adhesive thickness and adhesive Young's modulus

reference configuration, i.e. a glass thickness of 10 $\mathrm{mm}$ and a connector diameter of $50 \mathrm{~mm}$. The Poisson's ratio is kept constant on a value of 0.39 . The influence of the adhesive thickness and Young's modulus is illustrated in Fig. 13a for the maximal value of the maximal principal stress in the glass panel. With increasing Young's modulus of the adhesive, the maximum principal stress in the glass panel will rise. Also by reducing the adhesive thickness, the adhesive will behave more stiff and larger stress concentration will arise. However, the maximal deformation of the glass panel will decrease with increasing the adhesive stiffness, as is depicted in Fig. 13c. This phenomenon is also visible with decreasing adhesive thickness. Thick and flexible adhesive layers will increase the deformation capacity of the glass panel but the stresses in the glass panel will reduce due to the higher mobility of the connection. In contrast to thinner and stiffer adhesive layers which locally strengthen the connection and thus restrict the movement of the connection and introduce higher stresses and smaller deflections. From Fig. 13b, the adhesive Young's modulus has a larger influence on the maximal value of the principal stress in the adhesive layer than in the glass panel. The stress concentrations in the adhesive layer will increase more rapidly with increasing adhesive stiffness.

\subsection{Adhesive Poisson's ratio}

To investigate the influence of the Poisson's ratio, the adhesive layer is modelled with five values for the Poisson's ratio for each Young's modulus summarised in Table 7. The reference configuration, i.e. a glass thickness of $10 \mathrm{~mm}$ and a connector diameter of $50 \mathrm{~mm}$, is again used for the geometrical parameters. The adhesive thickness is kept constant on a value of $0.2 \mathrm{~mm}$. The influence of the adhesive Poisson's ratio is illustrated in Fig. 14a in function of the Young's modulus for the maximal value of the maximal principal stress in the glass panel. The influence of the Pois- 


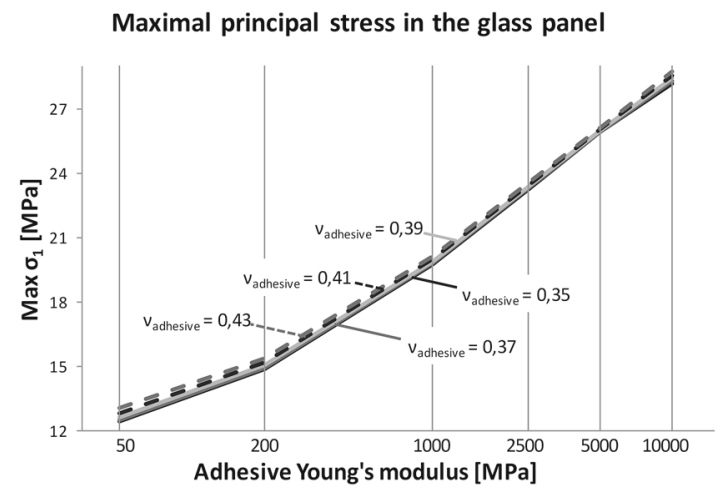

(a)

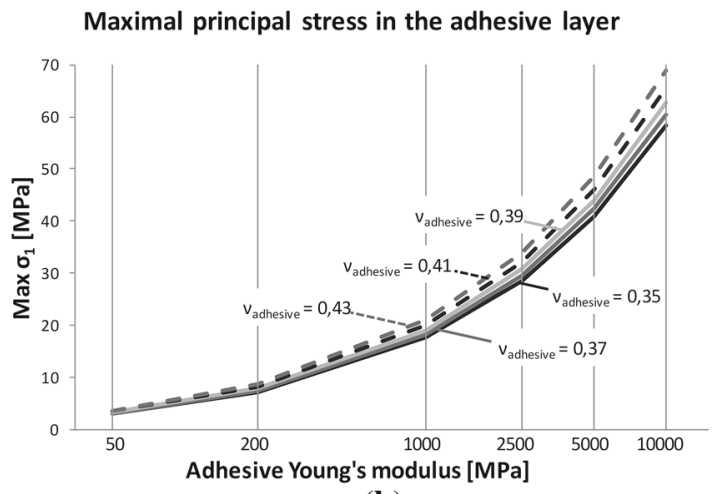

(b)

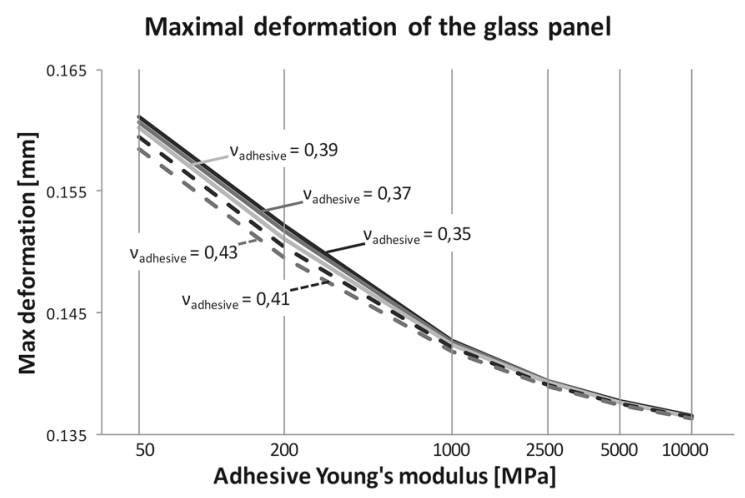

(c)

Fig. 14 Maximal value of the maximal principal stress in a the glass panel, $\mathbf{b}$ the adhesive layer and $\mathbf{c}$ the maximal deformation of the glass panel tin function of the adhesive Poisson's ratio and adhesive Young's modulus

son's ratio is rather small compared to the influence of the adhesive Young's modulus. A decrease in the adhesive Poisson's ratio will slightly reduce the maximal occurring stresses in the glass panel. The maximal values for the maximal principal stress in the adhesive layer is depicted in Fig. 14b. Also here the influence is small and the stress depends proportionally to the Poisson's ratio. This effect is almost only observable for larger values for the adhesive Young's modulus. The increase in stress with increasing adhesive Poisson's ratio can be attributed to the increase of the transversal deformation of the adhesive layer. However, this transversal deformation is constrained by the boundary conditions, i.e. the steel connector and the glass panel, resulting in an increase of the maximal principal stresses in the adhesive layer and glass panel. This observation was also noticeable in previous research (Dispersyn et al. 2015b). The maximal value for the deformation decreases with an increase of the adhesive Poisson's ratio.

\section{Conclusions}

In this work, the mechanical behaviour of adhesive point-fixings under uniaxial load is investigated. The entire connection is studied by supporting the glass panel at a circumference equal to 6 times the diameter of the connection. To gain a complete validated model, the experiments are performed with three different diameters $(30,50$ and $70 \mathrm{~mm})$ and three different glass thicknesses (4, 10 and $19 \mathrm{~mm})$. From the experiments, it can be concluded that the glass thickness is more determinative for more stiff adhesives.

The experimental results are used to validate a numerical model. For this validation, the strains in the glass panel and the deformation of the glass panel at three different distances from the centre are measured using strain gauges and LVDT's, respectively. The numerical analyses yield strain peaks and drops which were not visible in the experiments. This highlights the benefits and necessity of numerical investi- 
gation. The location of maximal strain is at the outside of the connector. This was also observed by the location of the crack initiation when the specimens fails due to glass failure. The crack initiation was mostly situated close to the connector. The numerical results correspond very well with the experimental values.

The obtained FEM model is then used to study more thoroughly the influence of geometrical parameters, such as the connection's diameter and glass thickness, and material parameters, such as the adhesive modulus of elasticity and the adhesive Poisson's ratio.

The results from this parametric study point out that the maximal occurring stresses will increase with a decrease of the connector diameter. A larger diameter will support the glass panel over a larger surface, resulting in lower stresses. However, specimens with a larger diameter will have a larger deflection. An increase in glass thickness will increase the moment of inertia of the panel. The increase of the rigidity of the panel will result in lower stresses and deformations. With increasing adhesive Young's modulus, the maximum principal stress in the glass panel will rise. By reducing the adhesive thickness, the adhesive will behave more stiff and larger stress concentration will arise. However, the maximal deformation of the glass panel will decrease with increasing the adhesive stiffness. Thick and flexible adhesive layers will increase the deformation capacity of the glass panel but the stresses in the glass panel will reduce due to the higher mobility of the connection. In contrast to thinner and stiffer adhesive layers which locally strengthen the connection and thus restrict the movement of the connection and introduce higher stresses and smaller deflections. The stress concentrations in the adhesive layer will increase more rapidly with increasing adhesive stiffness. The increase of the adhesive Poisson's ratio will result in an increase of the transversal deformation of the adhesive layer. Indeed, this transversal deformation is constrained by the boundary conditions, i.e. the steel connector and the glass panel, resulting in an increase of the maximal principal stresses in the adhesive layer and glass panel. However, this effect is rather small compared to the influence of the adhesive Young's modulus and the investigated geometrical parameters.

Summarizing, the maximal stresses occurring in the adhesive layer and glass panel will increase with a decrease of the connector diameter, the glass thickness and adhesive thickness, and with an increase of the adhesive stiffness and adhesive Poisson's ratio.
Furthermore, the maximal deformation of the glass panel can be reduced by increasing the glass thickness, adhesive stiffness and adhesive Poisson's ratio, and by decreasing the connection diameter and the adhesive thickness.

Acknowledgments The authors would like to thank the Flemish government agency for Innovation by Science and Technology (Grant No 121043) for funding the present research. Also the company $3 \mathrm{M}$ is gratefully acknowledged for providing the two-component epoxy 3M Scotch Weld $9323 \mathrm{~B} / \mathrm{A}$.

\section{Compliance with ethical standards}

Conflict of interest All the authors states that there is no conflict of interest.

\section{References}

3M: Technical Data Sheet $3 \mathrm{M}^{T M}$ Scotch-Weld ${ }^{T M} 9323$ B/A: Two part structural adhesive (2010)

Belis, J., Callewaert, D., Van Hulle, A.: Bouwen Met Glas en Adhesieven-Praktische gids voor ontwerper en uitvoerder (in Dutch). Ghent University, Ghent (2011a)

Belis, J., Van Hulle, A., Out, B., Bos, F., Callewaert, D., Poulis, H.: Broad Screening of Adhesives for Glass-Metal Bonds. In: Proceedings of Glass Performance Days, Tampere (2011b)

Beyer, J.: Ein Beitrag zum Bemessungskonzept für punktgestützte Glastafeln. Doctoral Dissertation, Technischen Universität Darmstadt (2007)

Bues, M., Bucak, Ö., Illguth, M.: Bonded point fixities for constructive architectural glass applications. In: Proceedings of Glass Performance Days, vol. 2009, pp. 250-253 (2009)

Christensen, R.M.: The Theory of Materials Failure. Oxford University Press, Oxford (2013)

Clark, J., McGregor, I.: Ultimate tensile stress over a zone: a new failure criterion for adhesive joints. J. Adhes. 42, 227-245 (1993). doi:10.1080/00218469308026578

Crocombe, A.D., Bigwood, D.A., Richardson, G.: Analysing structural adhesives joints for failure. Int. J. Adhes. Adhes. 10, 167-178 (1990). doi:10.1016/0143-7496(90)90100-C

Dean, G., Crocker, L., Read, B., Wright, L.: Prediction of deformation and failure of rubber-toughened adhesive joints. Int. J. Adhes. Adhes. 24, 295-306 (2004). doi:10.1016/j. ijadhadh.2003.08.002

Dispersyn, J., Van der Biest, T., Belis, J.: Experimental research on the failure of adhesive point-fixings between annealed and metal under uniaxial load. In: Proceedings of challenging glass 4 \& COST TU0905 final conference, pp. 339-346 (2014a)

Dispersyn, J., Belis, J., Sonck, D.: New glass design method for adhesive point-fixing applications. Proc. Inst. Civil Eng. Struct. Build. 1(11). (2014b) doi:10.1680/stbu.13.00103

Dispersyn, J., Belis, J., De Jaegher, J.: Influence of corner and edge distance of adhesive point-fixings for glass structures. Eng. Struct. 105, 174-185 (2015a). doi:10.1016/j.engstruct. 2015.09.037 
Dispersyn, J., Santarsiero, M., Belis, J., Louter, C.: A preliminary study of the nonlinearity of adhesive point-fixings in structural glass facades. J. Facade Des. Eng. 2(1-2), 85-108 (2015b). doi:10.3233/FDE-140015

Dodd, G.: Essential elements of bolted structural glass systems. Proceedings on ICBEST'97, 76(92) (1997)

ETAG 002.: Guideline for European technical approval for structural sealant glazing kits (SSGK)—Part 1: supported and unsupported systems, European Organisation for Technical Approvals (2012)

Feldmann, M., Kasper, R., Pils1, M.: Glass for Structural Applications - the development of the connection design. In: Proceedings of Challenging Glass, pp. 557-569 (2008)

Haldimann, M., Luible, A., Overend, M.: Structural use of glass. IABSE-AIPC-IVBH, Zürich, Switzerland (2008)

Lee, H.K., Pyo, S.H., Kim, B.R.: On joint strengths, peel stresses and failure modes in adhesively bonded double-strap and supported single-lap GFRP joints. Compos. Struct. 87(1), 44-54 (2009). doi:10.1016/j.compstruct.2007.12.005

Maniatis, I.: Numerical and experimental investigations on the stress distribution of bolted glass connections under inplane loads. Doctoral dissertation, Technische Universität München (2006)

Mocibob, D., Belis, J.: Coupled experimental and numerical investigation of structural glass panels with small slenderness subjected to locally introduced axial compression. Eng. Struct. 32(3), 753-761 (2010). doi:10.1016/j. engstruct.2009.12.003

Nielsen, J.H., Olesen, J.F., Poulsen, P.N., Stang, H.: Simulation of residual stresses at holes in tempered glass: a parametric study. Mater. Struct. 43(7), 947-961 (2010). doi:10.1617/ s11527-009-9558-z

Outeiro, J.C., Umbrello, D., M'saoubi, R.: Experimental and numerical modelling of the residual stresses induced in orthogonal cutting of AISI $316 \mathrm{~L}$ steel. Int. J. Mach. Tools Manuf. 46(14), 1786-1794 (2006). doi:10.1016/j. ijmachtools.2005.11.013

Overend, M.: Optimizing connections in structural glass. In: Proceedings of 2 nd international conference on glass in buildings (2005)
Overend, M., Nhamoinesu, S., Watson, J.: Structural performance of bolted connections and adhesively bonded joints in glass structures. Struct. Eng. 139(12), 04013015 (2013). doi:10.1016/(ASCE)ST.1943-541X.0000748

Santarsiero, M., Carvalho, P., Louter, C., Cruz, P.: Experimental and numerical investigations of metal-to-glass embedded connections with thin stainless steel plate. In: Proceedings of COST Action TU0905, mid-term conference on structural glass (2013)

Sasso, M., Palmieri, G., Chiappini, G., Amodio, D.: Characterization of hyperelastic rubber-like materials by biaxial and uniaxial stretching tests based on optical methods. Polym. Test. 27(8), 995-1004 (2008). doi:10.1016/j. polymertesting.2008.09.001

Siebert, B.: Anforderungen für ein Berechnungskonzept für die Bemessung punktgelagerter Verglasungen. Stahlbau 75(8), 652-657 (2006). doi:10.1002/stab.200610067

Siebert, G., Herrmann, T.: Glazing with countersunk point fittings. Proc. Chall. Glass 3, 335-348 (2010)

Sitte, S., Brasseur, M.J., Carbary, L.D., Wolf, A.T.: Preliminary evaluation of the mechanical properties and durability of transparent structural silicone adhesive (TSSA) for point fixing in glazing. J. ASTM Int. 8(10), 1-27 (2011). doi:10. 1520/JAI104084

Stumpf, F., Marczak, R.: Optimization of constitutive parameters for hyperelastic models satisfying the BakerEricksen inequalities. Mecánica Computacional 29, 29012916 (2010)

Tsai, M.Y., Morton, J.: The effect of a spew fillet on adhesive stress distributions in laminated composite single-lap joints. Compos. Struct. 32(1), 123-131 (1995). doi:10. 1016/0263-8223(95)00059-3

Vyzantiadou, M.A., Avdelas, A.V.: Point fixed glazing systems: technological and morphological aspects. J. Constr. Steel. Res. 60(8), 1227-1240 (2004). doi:10.1016/j.jcsr.2003.11. 005

Weller, B., Tasche, S.: Adhesive Fixing in Glass Construction. In: Proceedings of the 9th international conference on architectural and automotive glass, pp. 267-270 (2005) 